\title{
In vivo Raman Microspectroscopy: Intra- and Intersubject Variability of Stratum Corneum Spectral Markers
}

\author{
Alessia Quatela Lynda Miloudi Ali Tfayli Arlette Baillet-Guffroy \\ Laboratory of Lipids: Analytical and Biological Systems Lip(Sys) ${ }^{2}$, Group of Analytical Chemistry of Paris-Sud \\ (GCAPS), University Paris Sud, Université Paris-Saclay, Châtenay-Malabry, France
}

\section{Key Words}

Analysis of variance - In vivo Raman microspectroscopy · Interindividual variability · Skin measurements $\cdot$ Stratum corneum

\begin{abstract}
Background: In vivo Raman spectroscopy is a powerful tool for real-time analysis and in situ evaluation of tissues such as the skin. The efficiency of this technique has been widely demonstrated as a label-free method for in vivo evaluation of the skin. The aim of this study is to gather information about inter- and intra-individual variations in the spectral descriptors of water content and structure, organization of the lipid barrier and structure of proteins in the stratum corneum (SC). Methods: In vivo SC measurements were performed on 17 female volunteers aged 20-30 years (phototypes I and II). For intra-individual variability, spectral collection was performed on 5 successive days per volunteer. Shapiro-Wilk and Cochran tests were applied to check the normality and the homoscedasticity of variances. ANOVA was then applied to evaluate intra- and intergroup variability. Results: ANOVA was performed on the spectral descriptors of water content and structure, organization of the lipid barrier and secondary structure of proteins in the SC. No significant intra- and interday variability was observed for all volunteers. Despite the low value of the total relative standard deviation, a highly significant variation was observed
\end{abstract}

\section{KARGER}

E-Mail karger@karger.com

www.karger.com/spp between volunteers. Conclusion: Interindividual variability for Raman measurements is significant for a set of volunteers with normal nondiseased SC and close phototypes. This variability should be taken into consideration as a threshold for significant variance when working in vivo.

(c) 2016 S. Karger AG, Basel

\section{Introduction}

The noninvasive analysis of human skin by confocal Raman spectroscopy provides micro-level resolution and depth-resolved structural information of in vivo biological tissues. This technique has been applied to study a number of in vivo health-related phenomena in human tissue [1-4]; it provides a straightforward way to get better insight into the chemical structure and physical behavior of intrinsic molecular components of the stratum corneum (SC) $[5,6]$ and helps to follow up the penetration and action of exogenous molecules [7-11].

In this study, we will apply Raman spectroscopy to study skin variability in vivo, particularly in the outermost layer, the SC. The SC is the interface with the outside world and well recognized as the barrier that prevents unwanted materials from entering the body and excessive water loss of the body [12]. Franzen and Windbergs [13] explored the spectral variability of human SC ex vivo. 
The SC is composed of corneocytes, which are hexagonal flat cells filled with keratin, without nucleus, and held together by corneodesmosomes and lipid [12]. The lipids are arranged in lamellar sheets, which consist of lipid matrix composed mainly of ceramides, cholesterol, and fatty acids. Corneodesmosomes are specialized intercorneocyte linkages formed by proteins, and, together with the lipids, they maintain the integrity of the SC.

Using differential scanning calorimetry, Takenouchi et al. [14] demonstrated the presence of three types of water in the SC: tightly bound water, partially bound water and unbound water. In addition to the identification and quantification of the water type, the effect of the water content on SC composition and physiology has been investigated $[15,16]$. Since water enhances elasticity of the SC, water-keratin interactions have been investigated using techniques such as nuclear magnetic resonance imaging $[17,18]$ and cryo-scanning electron microscopy [19].

In clinical research, variabilities are usually classified into three categories: intra-subject variability, intersubject variability, and total variability. Intrasubject variability refers to the variability observed of repeated measurements in the same subject under the same experimental condition. The sources for intrasubject variability are multifold. Two important sources are biological variability and measurement errors. Theoretically, the intrasubject variability can be eliminated by repeating the experiment infinite times on the same subject under the same conditions. In practice, no experiment can be carried out infinite times - it can only be approximated by a large number of replicated experiments. However, even if we could repeat experiments an infinite number of times on every subject and take the average of replicates, which is called subject-specific mean value, we may still observe differences in the subject-specific mean values. This type of variability is completely due to the heterogeneity between subjects, which is referred to as the intersubject variability. Assuming that intra- and intersubject variabilities are independent of each other, the variability observed in a group of subjects is defined as total variability, which can be obtained as the sum of the intrasubject variability and the intersubject variability from the usual analysis of variance (ANOVA) model [20].

The objective of the present study is to evaluate the variability of SC Raman signal and physical properties in healthy subjects. We particularly addressed the question of the different sources of variability in order to determine the limits of reproducibility in SC in vivo Raman experiments.

Variability of in vivo Raman Descriptors in the Stratum Corneum

\section{Materials and Methods}

\section{Subjects}

A total of 17 female volunteers aged 20-30 years (mean 25 years) were enrolled in this study. All subjects presented Fitzpatrick's skin types I or II. Volunteers had no systemic or skin disorders which could influence skin surface $\mathrm{pH}$, hydration, and sebum content at the study sites. No skin care products were applied to the measured sites $72 \mathrm{~h}$ prior to the measurement, and the measured sites were not washed with soap or surfactant for at least $24 \mathrm{~h}$ prior to the study. After an acclimatization time $\left(22^{\circ} \mathrm{C}, 45 \%\right.$ relative humidity) of $10 \mathrm{~min}$, a template containing an aperture of $1 \mathrm{~cm}^{2}$ each in size was attached to the volunteers' volar forearms. Six measurements at different points of the aperture were performed in each volunteer. For intra-individual variability, spectral collection was performed on 5 successive days per volunteer. Each subject's sessions were scheduled at the same time of the day, and all subjects gave written informed consent prior to the beginning of experimentation.

\section{Biometric Measurements}

Skin surface temperature was measured by means of a noncontact infrared thermometer (ScanTemp440). Body mass index (BMI) as defined by the World Health Organization $\left(\mathrm{kg} / \mathrm{m}^{2}\right)$ was taken into consideration as additional physiological parameter. BMI varied from 17 to 33 in our volunteers.

\section{In vivo Raman Microprobe Measurements}

In vivo Raman investigations were performed using an in vivo confocal Raman optical microprobe (Horiba Jobin Yvon, Villeneuve d'Ascq, France) attached to a home-made movable arm allowing to easily position the probe on the skin surface.

The setup consisted of a 660 -nm laser diode [21] as excitation source delivering approximately $15 \mathrm{~mW}$ at the sample level, a probe head including interferential and edge band-pass filters for filtering incident laser line and Rayleigh scattering, respectively, and a long focal microscope objective MPLAN FLN $\times 100 /$ NA 0.75 (Olympus, Japan) for focusing the excitation beam and capturing the scattered light. The penetration depth was around $5 \mu \mathrm{m}$. The objective was coupled to a piezoelectric system, a 5 - $\mu$ m-diameter fiber-optic coupling with coaxial two-fiber probe, one for excitation and the other for collection. Collected scattered light was analyzed with a LabRAM HR Evolution (Horiba Jobin Yvon) spectrograph with a high-sensitivity CCD detector (Synapse; Horiba Jobin Yvon) cooled to $-70^{\circ} \mathrm{C}$ by Peltier effect and gratings of $300 \mathrm{~g} / \mathrm{mm}$, permitting to achieve a spectral resolution of $4 \mathrm{~cm}^{-1}$ on a spectral range from 400 to $3,800 \mathrm{~cm}^{-1}$. For each scan, a 2-second exposure time was used with 2 accumulations.

\section{Statistics}

All spectra were smoothed using the Savitzky-Golay algorithm (2nd order, 11 points) [22], baseline corrected using an automatic polynomial function, and then normalized by applying the unit vector method.

Spectra have been separated into two wave number regions: the so-called fingerprint region $\left(400-1,800 \mathrm{~cm}^{-1}\right)$ and the region from 2,600 to $3,800 \mathrm{~cm}^{-1}$, normalized on amide I band $(1,565-1,720$ $\left.\mathrm{cm}^{-1}\right)$ and on $\mathrm{C}-\mathrm{H}$ stretching band $\left(2,800-3,030 \mathrm{~cm}^{-1}\right)$, respectively [23]. The bands that were used as reference exhibited minimal intensity and bandwidth variation between the spectra [24].

Skin Pharmacol Physiol 2016;29:102-109 


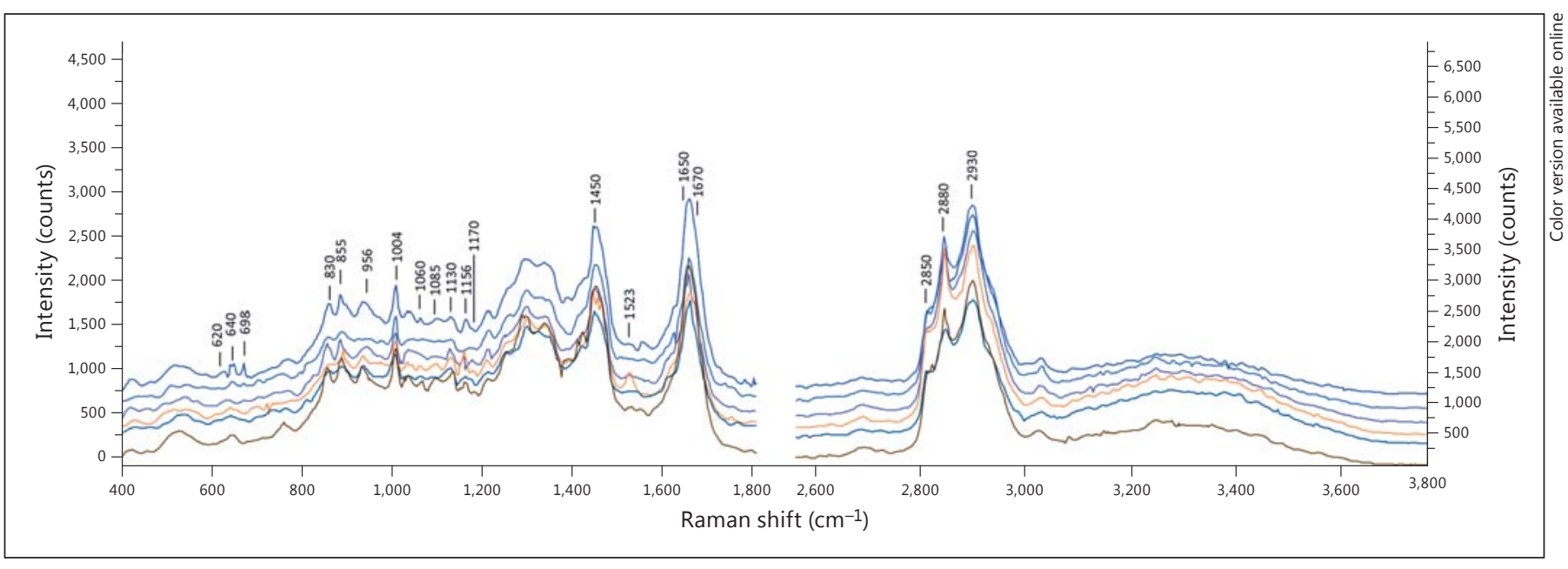

Fig. 1. Raman spectra of the surface of the forearm.

Curve fitting of the $\mathrm{OH}$ stretching band has been carried out using the least-square fitting algorithm. The algorithm allows the user to identify a number of subbands within a spectral region using the second derivative. It then automatically adjusts the combination of bands to best fit the spectral profile. The maximum shift of the subband position was set to $\pm 5 \mathrm{~cm}^{-1}$ and the bandwidth was fixed to 40 $\mathrm{cm}^{-1}$, while intensity was left free to adapt to the fit. The quality of the fit was estimated by the standard error and the $\chi^{2}$ values [25].

Total variation was estimated for each Raman descriptor by calculating the percentage of the relative standard deviation (RSD).

Homogeneity of variance is a major assumption underlying the validity of many parametric tests. More importantly, it serves as the null hypothesis in substantive studies that focus on inter- or intragroup dispersion. We performed Cochran's C test to identify and study the homogeneity of the variances before performing ANOVA.

ANOVA is one of the most widely used tests for experimental data. It is a powerful method to compare differences between the means of several groups. The test compares the variability of each population (intragroup variances) and of grouped populations (intergroup variance), and thus determines whether the groups are significantly different. Two-way ANOVA has been applied for inter-and intragroup variation with a $5 \%$ level of significance for all skin parameters, which have been presented as means \pm SD.

The different data analysis steps were performed using MATLAB (MathWorks, Natick, Mass., USA).

\section{Results}

Different spectral features representative of the SC barrier function have been used to study the behavior upon application of the protocol. Figure 1 displays in vivo Raman spectra of the volar aspect of the forearm in which the Raman signature of the numerous SC constituents is well defined.

Bands assignment consistent with Raman spectra in figure 1 are given in online supplementary table 1 (see www.karger.com/doi/10.1159/000445079 for all online suppl. material). Generally, our Raman assignments correlate with those in the literature [26-46]. The Raman spectrum of the SC is dominated by vibrational bands of its structural proteins, lipids, and tissue water.

In order to investigate the biochemical changes in the SC, we focused our study on the following different spectral features:

- The $v_{\text {asym }} \mathrm{CH}_{2}\left(2,880 \mathrm{~cm}^{-1}\right) / v_{\text {sym }} \mathrm{CH}_{2}\left(2,850 \mathrm{~cm}^{-1}\right)$ ratio, generally used as an indicator for both conformational state and lateral packing. High values are associated with higher transcontent and a compact organization $[43,44,46]$.

- The $v(\mathrm{C}-\mathrm{C})$ skeletal optical mode in the 1,050- to $1,140-\mathrm{cm}^{-1}$ region, related to the presence of trans or gauche conformers inside the acyl chains. The trans/ gauche conformer ratio was analyzed by calculating the S1130 + S1060/S1085 ratio. High values of this ratio are associated with a compact state in lipid packing while a decrease is indicative of loosening [43].

- The protein secondary structure was examined through analysis of the amide I band. It can be deconvoluted into several subbands associated with different forms of secondary structure, i.e. $\alpha$-helix, $\beta$-sheet, turns and random coil structures [46].

- The maximum position of $v_{\text {asym }} \mathrm{CH}_{3}: 2,930 \mathrm{~cm}^{-1}$, an indicator of the folding/unfolding process of proteins. 
Folding of the proteins can be highlighted by a shift towards lower wave numbers.

- The spectral features associated with the different types of water were assessed by performing a band deconvolution of the $v(\mathrm{O}-\mathrm{H})$ band in the range of 3,100$3,600 \mathrm{~cm}^{-1}$. The subbands in the range of 3,245-3,420 $\mathrm{cm}^{-1}$ are associated with partially bound water. Partially bound water is bound to the first monolayer and to other SC molecular components. This means that water molecules interact partially with neighboring molecules using only 2 or 3 of the 4 possible hydrogen bonds.

Unbound water is considered as water that is not directly linked to the SC components, thus presenting no hydrogen bonds with SC lipids or proteins. $\mathrm{OH}$ stretching associated with this water arises around 3,420-3,600 $\mathrm{cm}^{-1}$. The ratio between unbound water and partially bound water has been calculated [26].

Selected Raman descriptors of human SC are given in online supplementary table 1.

In order to successfully assess results obtained from in vivo measurement campaigns, it is crucial to consider variations in the signals that might be induced by external factors. Inter- and intraday variabilities were first investigated for each volunteer. Values of $\mathrm{p}<0.05$ were considered statistically significant.

As can been observed in figure 2, no significant variation can be observed over the 5 days, neither in lipid organization $(\mathrm{p}=0.71)$, conformational order $(\mathrm{p}=0.52)$, proteins folding $(\mathrm{p}=0.91)$ or secondary structure $(\mathrm{p}=$ $0.39)$ nor in water content $(\mathrm{p}=0.47)$ or water structure $(\mathrm{p}=0.54)$.

This result shows the reproducibility of the in vivo Raman measurements and the stability of the physiological state of the skin for a short period. The interday parameter can be omitted in in vivo investigations.

In order to reduce the parameters that can influence interindividual variability, we selected only female volunteers aged between 20 and 30 years with close skin phototypes and performed measurements on the inner forearm after 10 min of acclimatization.

Total variation was calculated based on the percentage of RSD for each Raman descriptor and gave $8 \%$ relative variability for both the lipid organization descriptor $\left[v_{\text {asym }} \mathrm{CH}_{2}\left(2,880 \mathrm{~cm}^{-1}\right) / v_{\text {sym }} \mathrm{CH}_{2}\left(2,850 \mathrm{~cm}^{-1}\right)\right.$ ratio] and the $\beta$-sheet/a-helix ratio $\left(1,670 \mathrm{~cm}^{-1} / 1,650 \mathrm{~cm}^{-1}\right)$. The total variation in the water structure ratio (unbound/partially bound water) was around $15 \%$, while the descriptor of the conformational order of lipids $\left[\left(1,060 \mathrm{~cm}^{-1}+1,130\right.\right.$ $\left.\mathrm{cm}^{-1}\right) / 1,085 \mathrm{~cm}^{-1}$ ] varied almost $22 \%$.

Variability of in vivo Raman Descriptors in the Stratum Corneum
Despite the relatively low RSD value, global Raman signature based on area under curve (AUC) from 400 to $1,800 \mathrm{~cm}^{-1}$ and from 2,800 to $4,000 \mathrm{~cm}^{-1}$ revealed high variability between volunteers (online suppl. fig. 1). Moreover, spectral descriptors directly related to physiological parameters showed highly significant variability with values of $\mathrm{p}<10^{-5}$ (fig. 3 ).

To investigate the possible source of variability, semiquantitative analyses of skin characteristics were carried out: contents of the lipid classes, protein conformation and hydration results of the Raman signal were directly correlated to skin temperature, BMI and age (fig. 4).

Pearson's correlation coefficient ( $r$ ) was calculated to evaluate the linear relation between Raman spectral markers and intra- and interindividual physiological parameters, where $r=1$ indicates a perfect correlation while $r>0.9$ is considered to describe an excellent correlation.

In the correlation matrix (fig. 4), each $r$ value is represented by a color pixel. The color scale varied from 0 (no correlation) to 0.8 .

The Raman spectral markers presented in the y-axis can be divided into three main groups, (i) water content and structure markers (AUC-OH, unbound water, partially bound water, and unbound/partially bound water ratio); (ii) lipid markers: [CH stretching, lipid conformational order (trans/gauche), and compactness] and (iii) protein markers (secondary structure with the amide I band and the $\beta$-sheet/ $\alpha$-helix ratio, and protein folding).

As the vibrational features are sensitive to physiological characteristics like $\mathrm{pH}$, skin hydration status, and small variations in the relative amount of lipid classes [47], the spectral markers presented in the y-axis cannot have individual correlation coefficients $>0.9$ with temperature, age, and BMI. Therefore, even if $\mathrm{r}=0.8$ refers statically to a fair correlation, it gives an indication for good interrelated information.

After 10 min of acclimatization at room temperature, the skin surface temperature varied from 23 to $26^{\circ} \mathrm{C}$ and seemed not to interrelate with Raman descriptors. Meanwhile, the lipid conformational order was apparently sensitive to slight temperature variations $(r>0.6)$.

Despite the relatively limited age range (20-30 years), different Raman descriptors showed fair correlations (mainly the $\mathrm{CH}$ stretching band followed by the unbound water fraction, and the secondary structure of proteins: $r>0.6)$.

Finally, the highest correlation coefficient was obtained between water content ( $\mathrm{OH}$ stretching) and water structure (unbound and partially bound) with the BMI $(\mathrm{r}=0.8)$.

Skin Pharmacol Physiol 2016;29:102-109 


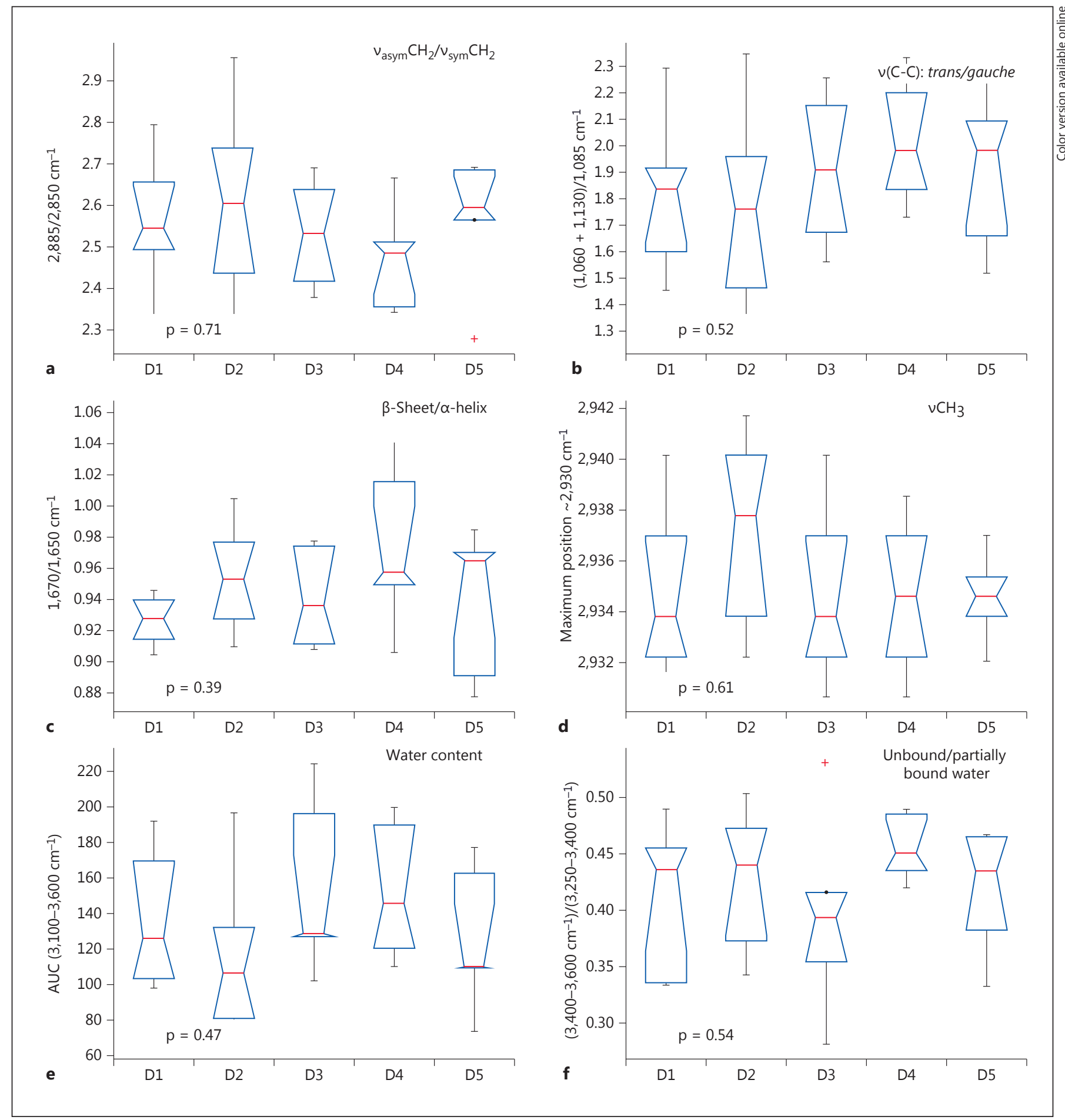

Fig. 2. Interday data variability for the $v_{\text {asym }} \mathrm{CH}_{2} / v_{\text {sym }} \mathrm{CH}_{2}$ ratio (a); $v(\mathrm{C}$-C) skeletal optical mode (b); the $\beta$-sheet/ $\alpha$-helix subband ratio (c); maximum position of $v_{\text {asym }} \mathrm{CH}_{3}(\mathbf{d})$; AUC of the $v(\mathrm{O}-\mathrm{H})$ band region (e), and the unbound/partially bound water ratio (f) from days 1 (D1) to 5 (D5). Data are expressed as means \pm SD. Statistical analysis was performed by two-way ANOVA. 


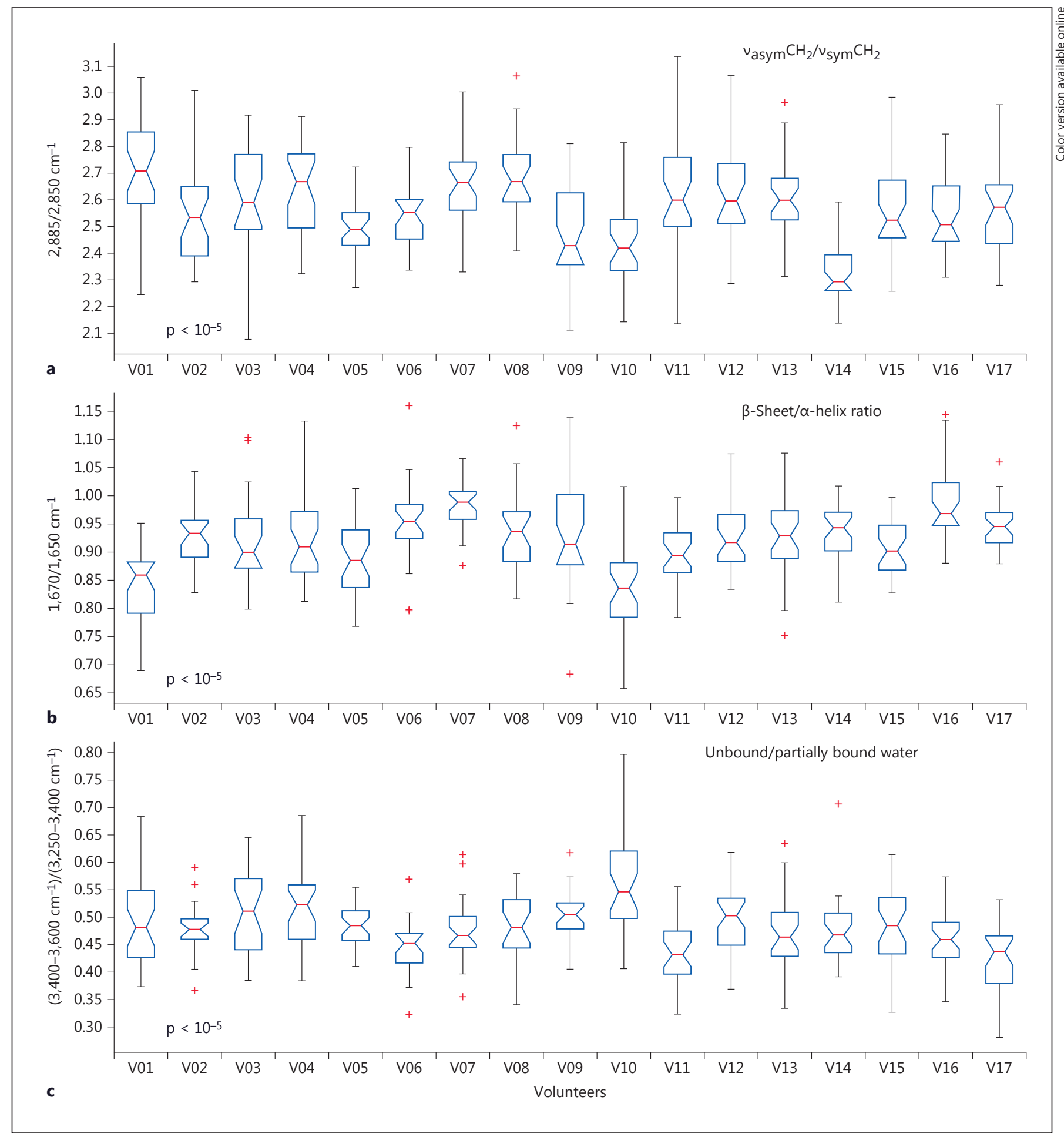

Fig. 3. Intersubject variability for the $v_{\text {asym }} \mathrm{CH}_{2} / v_{\text {sym }} \mathrm{CH}_{2}$ ratio (a); the $\beta$-sheet/ $\alpha$-helix subband ratio (b), and the unbound/partially bound water ratio $(\mathbf{c})$. 


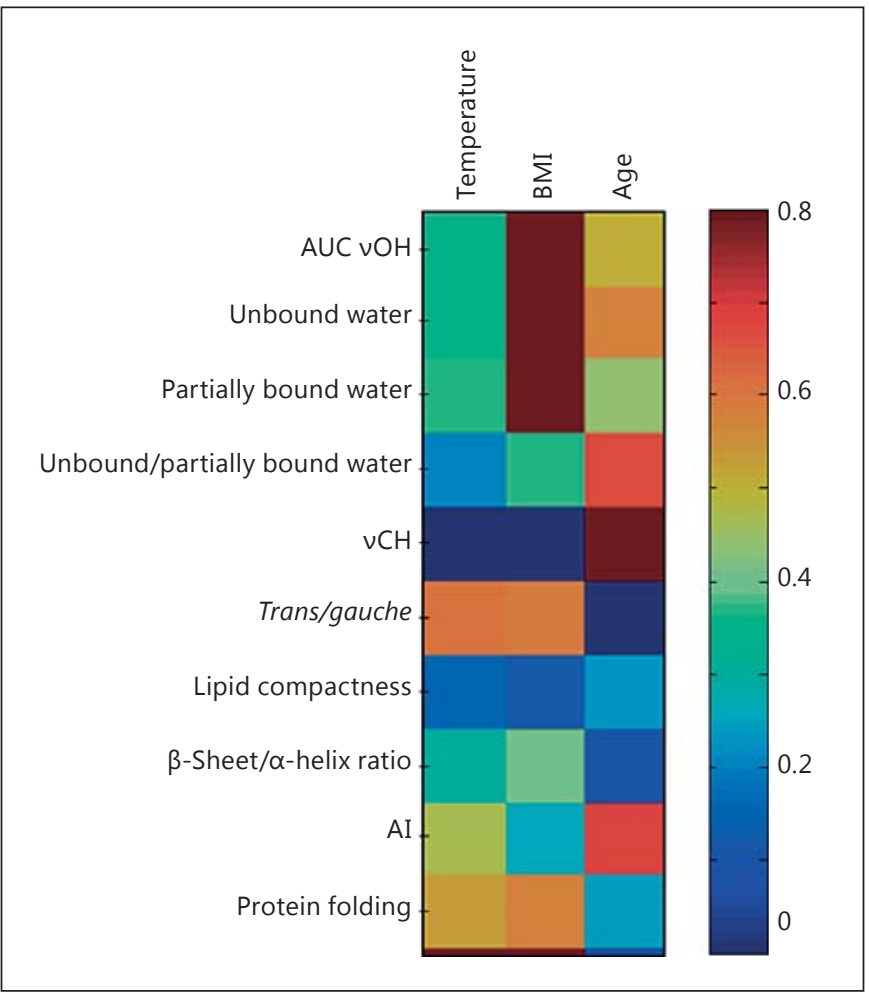

Fig. 4. Correlation matrix between SC spectral markers and biometrical data. $\mathrm{AI}=$ Amide I band.

The range of measurements for each parameter was small (age: $20-30$ years, BMI: $17-33$, and temperature: $23-26^{\circ} \mathrm{C}$ ), and consequently the power of the statistical analysis was weak. A larger study with higher variability in biometrical parameters including complementary physiological information is required to validate these observations.
Consequently, our findings affirm that physiological and physical parameters, as BMI and age, should be taken into account during the recruitment of volunteers.

\section{Conclusion}

In this study, we investigated the in vivo Raman spectral variability of different spectral markers in the human skin. Intra- and interday variability was considered not statistically significant. This proved the stability of the physiological state of the skin for a short period and the reliability of our experimental method.

Despite a relatively low total RSD, the detailed analysis of 6 spectral features revealed high variability between volunteers. Furthermore, the dependence of intragroup variability in the physiological status, especially BMI, should be considered when recruiting volunteers for future studies to avoid unnecessary bias to the analysis.

\section{Acknowledgment}

The study was financially supported by the Agence Nationale de la Recherche (ANR-12-JSV5-003 CARE).

\section{Statement of Ethics}

All volunteers gave informed written consent to the experiments. All procedures were in accordance with the Helsinki Declaration.

\section{Disclosure Statement}

The authors have no financial conflicts of interest regarding the content of this paper.

\section{References}

1 Bauer NJ, Wicksted JP, Jongsma FH, March WF, Hendrikse F, Motamedi M: Noninvasive assessment of the hydration gradient across the cornea using confocal Raman spectroscopy. Invest Ophthalmol Vis Sci 1998;39:831835.

2 Egawa M, Hirao T, Takahashi M: In vivo estimation of stratum corneum thickness from water concentration profiles obtained with Raman spectroscopy. Acta Derm Venereol 2007;87:4-8.

3 Caspers PJ, Williams AC, Carter EA, Edwards HG, Barry BW, Bruining HA, Puppels GJ: Monitoring the penetration enhancer di- methyl sulfoxide in human stratum corneum in vivo by confocal Raman spectroscopy. Pharm Res 2002;19:1577-1580.

4 Wang H, Lee AM, Lui H, McLean DI, Zeng H: A method for accurate in vivo micro-Raman spectroscopic measurements under guidance of advanced microscopy imaging. Sci Rep 2013;3:1890.

5 Kikuchi S, Aosaki T, Bito K, Naito S, Katayama Y: In vivo evaluation of lateral lipid chain packing in human stratum corneum. Skin Res Technol 2015;21:76-83.

6 Forster M, Bolzinger MA, Rovere MR, Damour O, Montagnac G, Briançon S: Con- focal Raman microspectroscopy for evaluating the stratum corneum removal by 3 standard methods. Skin Pharmacol Physiol 2011; 24:103-112.

7 Egawa M, Sato Y: In vivo evaluation of two forms of urea in the skin by Raman spectroscopy after application of urea-containing cream. Skin Res Technol 2015;21:259264

8 Egawa M, Iwaki H: In vivo evaluation of the protective capacity of sunscreen by monitoring urocanic acid isomer in the stratum corneum using Raman spectroscopy. Skin Res Technol 2008;14:410-417. 
9 Choe C, Lademann J, Darvin ME: Analysis of human and porcine skin in vivo/ex vivo for penetration of selected oils by confocal Raman microscopy. Skin Pharmacol Physiol 2015;28:318-330.

10 Choe C, Lademann J, Darvin ME: Gaussianfunction-based deconvolution method to determine the penetration ability of petrolatum oil into in vivo human skin using confocal Raman microscopy. Laser Physics 2014;24: 105601.

11 Essendoubi M, Gobinet C, Reynaud R, Angiboust JF, Manfait M, Piot O: Human skin penetration of hyaluronic acid of different molecular weights as probed by Raman spectroscopy. Skin Res Technol 2016;22:55-62.

12 Menon GK, Cleary GW, Lane ME: The structure and function of the stratum corneum. Int J Pharm 2012;435:3-9.

13 Franzen L, Windbergs M: Accessing Raman spectral variability in human stratum corneum for quantitative in vitro depth profiling. J Raman Spectrosc 2013;45:82-88.

14 Takenouchi M, Suzuki H, Tagami H: Hydration characteristics of pathologic stratum corneum - evaluation of bound water. J Invest Dermatol 1986;87:574-576.

15 Mao-Qiang M, Feingold KR, Elias PM: Exogenous lipids influence permeability barrier recovery in acetone-treated murine skin. Arch Dermatol 1993;129:728-738.

16 Rawlings AV: Trends in stratum corneum research and the management of dry skin conditions. Int J Cosmet Sci 2003;25:63-95.

17 Rawlings AV, Matts PJ: Stratum corneum moisturization at the molecular level: an update in relation to the dry skin cycle. J Invest Dermatol 2005;124:1099-1110.

18 Jokura Y, Ishikawa S, Tokuda H, Imokawa G: Molecular analysis of elastic properties of the stratum corneum by solid-state ${ }^{13} \mathrm{C}$-nuclear magnetic resonance spectroscopy. J Invest Dermatol 1995;104:806-812.

19 Silva CL, Topgaard D, Kocherbitov V, Sousa JJ, Pais AA, Sparr E: Stratum corneum hydration: phase transformations and mobility in stratum corneum, extracted lipids and isolated corneocytes. Biochim Biophys Acta 2007; 1768:2647-2659.

20 Bouwstra JA, de Graaff A, Gooris GS, Nijsse J, Wiechers JW, van Aelst AC: Water distribution and related morphology in human stratum corneum at different hydration levels. J Invest Dermatol 2003;120:750-758.

21 Tfaili S, Gobinet C, Josse G, Angiboust J-F, Manfait M, Piot O: Confocal Raman microspectroscopy for skin characterization: a comparative study between human skin and pig skin. Analyst 2012;137:3673-3682.
22 Tfaili S, Gobinet C, Angiboust JF, Manfait M, Piot O: Raman microimaging using a novel multifiber-based device: a feasibility study on pharmaceutical tablets. Int J Spectrosc 2012; 474639:5.

23 Savitzky A, Golay MJE: Smoothing and differentiation of data by simplified least square procedures. Anal Chem 1964;36:1627-1639.

24 Quatela A, Tfayli A, Baillet-Guffroy A: Examination of the effect of stratum corneum isolation process on the integrity of the barrier function: a confocal Raman spectroscopy study. Skin Res Technol 2016;22:75-80.

25 Tosato MG, Alves RS, Dos Santos EA, Raniero L, Menezes PF, Belletti KM, Praes CE, Martin AA: Raman spectroscopic investigation of the effects of cosmetic formulations on the constituents and properties of human skin. Photomed Laser Surg 2012;30:85-91.

26 Vyumvuhore R, Tfayli A, Biniek K, Duplan H, Delalleau A, Manfait M, Dauskardt R, BailletGuffroy A: The relationship between water loss, mechanical stress, and molecular structure of human stratum corneum ex vivo. J Biophotonics 2015;8:217-225.

27 Barry BW, Edwards HGM, Williams AC: Fourier transform Raman and infrared vibrational study of human skin: assignment of spectral bands. Raman Spectrosc 1992;23: 641-645.

28 Biswas N, Waring AJ, Walther FJ, Dluhy RA: Structure and conformation of the disulfide bond in dimeric lung surfactant peptides SPB1-25 and SP-B8-25. Biochim Biophys Acta 2007; 1768:1070-1082.

29 Ermakov IV, Ermakova MR, Gellermann W, Lademann J: Noninvasive selective detection of lycopene and beta-carotene in human skin using Raman spectroscopy. J Biomed Opt 2004;9:332-338.

30 Gniadecka M, Faurskov Nielsen O, Christensen DH, Wulf HC: Structure of water, proteins, and lipids in intact human skin, hair, and nail. J Invest Dermatol 1998;110:393398.

31 Kuzuhara A: Protein structural changes in keratin fibers induced by chemical modification using 2-iminothiolane hydrochloride: a Raman spectroscopic investigation. Biopolymers 2005;79:173-184

32 Kuzuhara A, Hori T: Reduction mechanism of L-cysteine on keratin fibers using microspectrophotometry and Raman spectroscopy. Biopolymers 2005;79:324-334.

33 Lin SJ, Jee SH, Kuo CJ, Wu RJ, Lin WC, Chen JS, Liao YH, Hsu CJ, Tsai TF, Chen YF, Dong CY: Discrimination of basal cell carcinoma from normal dermal stroma by quantitative multiphoton imaging. Opt Lett 2006;31: 2756-2758

34 Lippert JL, Peticolas WL: Laser Raman investigation of the effect of cholesterol on conformational changes in dipalmitoyl lecithin multilayers. Proc Natl Acad Sci USA 1971;68: 1572-1576.
35 MacKie RM: An aid to the preoperative assessment of pigmented lesions of the skin. $\mathrm{Br}$ J Dermatol 1971;85:232-238.

36 Mathlouthi M, Seuvre AM, Koenig JL: F.t.-i.r. and laser-Raman spectra of guanine and guanosine. Carbohydr Res 1986;146:15-27.

37 Mathlouthi M, Seuvre AM, Koenig JL: F.t.-i.r. and laser-Raman spectra of cytosine and cytidine. Carbohydr Res 1986;146:1-13.

38 McIntosh LM, Jackson M, Mantsch $\mathrm{HH}$ Stranc MF, Pilavdzic D, Crowson AN: Infrared spectra of basal cell carcinomas are distinct from non-tumor-bearing skin components. J Invest Dermatol 1999;112:951-956.

39 Mirrashed F, Sharp JC: In vivo morphological characterisation of skin by MRI micro-imaging methods. Skin Res Technol 2004;10:149160

40 Neubert R, Rettig W, Wartewig S, Wegener M, Wienhold A: Structure of stratum corneum lipids characterized by FT-Raman spectroscopy and DSC. II. Mixtures of ceramides and saturated fatty acids. Chem Phys Lipids 1997;89:3-14.

41 Percot A, Lafleur M: Direct observation of domains in model stratum corneum lipid mixtures by Raman microspectroscopy. Biophys J 2001;81:2144-2153.

42 Vyumvuhore R, Tfayli A, Duplan H, Delalleau A, Manfait M, Baillet-Guffroy A: Effects of atmospheric relative humidity on stratum corneum structure at the molecular level: ex vivo Raman spectroscopy analysis. Analyst 2013;138:4103-4111.

43 Guillard E, Tfayli A, Manfait M, Baillet-Guffroy A: Thermal dependence of Raman descriptors of ceramides. Part II. Effect of chains lengths and head group structures. Anal Bioanal Chem 2011;399:1201-1213.

44 Tfayli A, Guillard E, Manfait M, Baillet-Guffroy A: Thermal dependence of Raman descriptors of ceramides. Part I. Effect of double bonds in hydrocarbon chains. Anal Bioanal Chem 2010;397:1281-1296.

45 Tfayli A, Piot O, Draux F, Pitre F, Manfait M Molecular characterization of reconstructed skin model by Raman microspectroscopy: comparison with excised human skin. Biopolymers 2007;87:261-274.

46 Tfayli A, Guillard E, Manfait M, Baillet-Guffroy A: Raman spectroscopy: feasibility of in vivo survey of stratum corneum lipids, effect of natural aging. Eur J Dermatol 2012;22:3641.

47 Vyumvuhore R, Tfayli A, Piot O, Le Guillou M, Guichard N, Manfait M, Baillet-Guffroy A: Raman spectroscopy: in vivo quick response code of skin physiological status. J Biomed Opt 2014;19:111603.
Variability of in vivo Raman Descriptors in the Stratum Corneum
Skin Pharmacol Physiol 2016;29:102-109 DOI: $10.1159 / 000445079$ 